Kolber, M.'; Chate, S. C. ${ }^{2}$; Leite, C. F. S. ${ }^{3}$

\section{1 - Tempo de sangria e coagulação em pré- operatório de animais atendidos no Hospital Veterinário da Faculdade de Medicina Veterinária da Universidade Paulista}

1- Professor responsável pela disciplina de Patologia Clínica da Faculdade de Medicina Veterinária da Universidade Paulista, São Paulo-SP

2- M.V. do Hospital Veterinário da Faculdade de Medicina Veterinária da Universidade Paulista, São Paulo-SP

3- Coordenador dos Cursos de Ciências da Computação e Sistemas de Informação da Universidade Paulista, São Paulo-SP

Com o avanço dos conhecimentos e da pesquisa em Medicina Veterinária, os exames que precedem as cirurgias têm-se mostrado fundamentais como meio de prevenção de acidentes no trans e no pós-operatório. Entre estes exames estão a determinação do tempo de sangria e do tempo de coagulaçào, que podem identificar afecçòes que interferem na cascata de coagulação e que podem permanecer sutilmente assintomáticas. Desta forma, procuramos demonstrar a eficiência, a simplicidade e o baixo custo destes exames e ainda comparar dois métodos de análise para o tempo de coagulação. As determinações do tempo de sangria (Método de Duke) e do tempo de coagulação [método da lâmina e o método do tubo de ensaio (Lee \& White)] foram realizadas como exames pré-operatórios em 20 animais da espécie canina sem raça definida, sendo 15 fêmeas e 5 machos, atendidos no Hospital Veterinário da Faculdade de Medicina Veterinária da Universidade Paulista, que seriam submetidos posteriormente a diferentes procedimentos cirúrgicos. No exame para a determinação do tempo de sangria, uma orelha de cada animal foi desinfetada com álcool e lancetada com agulha $25 \times 7$, sendo neste momento um cronômetro disparado e a cada 15 segundos um papel de filtro Watman $n^{\circ} 40$ era encostado no local da punçào, com cuidado de nào realizar pressão digital, evitando assim hemostasia; o cronômetro era parado quando o papel de filtro não apresentava mais sangue. Para determinação do tempo de coagulaçào pelo método da lâmina ou do tubo de ensaio, coletou-se sangue com agulha $25 \times 7$ e seringa de plástico sendo imediatamente disparado um cronômetro; uma gota de sangue era então colocada em lâmina de vidro e aproximadamente $2 \mathrm{ml}$ de sangue em um tubo de hemólise; a lâmina foi inclinada a cada 30 segundos e o tubo de hemólise a cada 60 segundos, até a formaçào de coágulo, tanto na lâmina como no tubo, sendo cada aferição marcada separadamente. Observamos que o tempo de sangria dos animais examinados apresentou resultados normais de acordo com os valores de referência consultados; assim também ocorreu com o tempo de coagulação, porém com a utilização do Teste t (Student), notamos que houve diferença significativa ao nivel de $5 \%(\mathrm{p}<0,05)$ entre os métodos utilizados para determinar o tempo de coagulação, sendo o tempo médio de coagulação da lâmina menor que o tempo de coagulação do tubo, existindo ainda uma forte correlação entre os dois.

\section{2 - Alterações clínicas e cardiopulmonares produzidas pelo envenenamento escorpiônico em cães}

Cordeiro, F. F.'; Sakate, M.'
1- Faculdade de Medicina Veterinária da Universidade Estadual Paulista, Campus de Botucatu, Botucatu-SP

O escorpionismo é um problema comum que acomete países tropicais e subtropicais e que assume grande importância médico-sanitária devido à sua fatalidade sobre aqueles individuos mais sensiveis. No Brasil, a principal espécie de escorpião envolvida em acidentes é o Tityus serrulatus, sendo que o potencial letal do envenenamento reside nas graves alteraçòes cardiopulmonares que o veneno escorpiônico é capaz de gerar. $\mathrm{O}$ envolvimento miocárdico 